\title{
Antrenmanın 13-14 Yaş Adölesanlarda Solunum Sistemi Üzerine Etkileri*
}

\author{
Tuba Melekoğlu ${ }^{1, \dagger}$, Ali Işın², Gürcan Ünlü ${ }^{3}$ \\ ${ }^{1}$ Akdeniz Üniversitesi, Spor Bilimleri Fakültesi, ORCID ID: 0000-0001-9223-8849 \\ ${ }^{2}$ Akdeniz Üniversitesi, Spor Bilimleri Fakültesi, ORCID ID: 0000-0003-4666-2117 \\ ${ }^{3}$ Orta Doğu Teknik Üniversitesi, Beden Eğitimi ve Spor Bölümü, ORCID ID: 0000-0002-2312-778X
}

$\ddot{\mathbf{O} z}$

Orijinal Makale

$\mathrm{Bu}$ çalışmanın amacı; okuldaki beden eğitimi derslerine ek olarak okul dışındaki fiziksel aktivitelere katılan 13-14 yaşındaki adölasanların akciğer hacim ve kapasitelerini, okul dışı fiziksel aktivitelere katılmayan adölasanlarla kıyaslamaktır. Antrenman geçmişlerine, sağlık durumlarına, fiziksel özelliklerine bağlı ön değerlendirme sonrasında atletizm, futbol, hentbol, yüzme gibi branşlarda en az 5 yıllık antrenman geçmişine sahip 28 sporcu ve antrenman geçmişi bulunmayan, sporcularla benzer fiziksel özelliklere sahip 28 sedanter adölasan katılmıştır. Akciğer hacim ve kapasitelerini belirlemek için spirometre ile vital kapasite, zorlu vital kapasite ve maksimal istemli ventilasyon ölçümleri yapılmıştır. Verilerin istatistiksel değerlendirilmesinde SPSS v.24 kullanılmıştır. Beden eğitimi derslerine ek olarak okul dışında da takım antrenmanlarına katılarak fiziksel aktivite düzeylerini arttıran adölasanların sadece beden eğitimi derslerine katılan adölasanlara karşın sırasıyla vital kapasiteleri $(3,57 \pm 0,63$ lt'ye karşın 2,72 $\pm 0,56$ lt), zorlu vital kapasiteleri $(3,50 \pm 0,64$ lt'ye karşın 2,70 $\pm 0,56 \mathrm{lt})$ ve maksimal istemli ventilasyon $(127,91 \pm 29,48 \mathrm{lt} / \mathrm{dk}, 109,10 \pm 19,07$ lt/dk) değerleri anlamlı olarak yüksek bulunmuştur $(\mathrm{p}<0,001)$. Okul dışında da fiziksel olarak aktif adölasanların vital kapasiteleri \% 31,50, zorlu vital kapasiteleri \% 29,82 ve maksimal istemli ventilasyon değerleri \% 17,24 daha yüksek bulunmuştur. Sonuçlar, adölasan ve ergenlik dönemindeki düzenli aktivitenin akciğer hacimlerini ve kapasitelerini artırdığını göstermektedir. Bu nedenle, adölasanların okuldaki beden eğitimi ders saatlerinin ve/veya okul dışındaki fiziksel aktivite düzeylerinin arttırılması solunum sistemi ve sağlığı üzerine

DOI: $10.30769 /$ usbd.414833 önemli katkılar sağlayacağı öngörülmektedir.

\section{The Effects of Training on Respiratory System of Adolescents Aged 13-14}

\begin{abstract}
The aim of this study was to compare the lung volumes and respiratory functions of the children aged 13-14 who joined additionally out-of-school physical activities and the others joined physical activities just in-school. Adolescents who had joined additionally athletics, football, handball or swimming training at least 5 years regularly and not-involved additionally physical activities participated in the study. Pulmonary function tests such as vital capacity, forced vital capacity and maximal voluntary ventilation were measured by spirometer to evaluate the respiratory volumes and functions. SPSS v.24 was used for statistical analysis. Vital capacity $(3,57 \pm 0,63 \mathrm{lt}$ vs. $2,72 \pm 0,56 \mathrm{lt})$, forced vital capacity $(3,50 \pm$ $0,64 \mathrm{lt}$ vs. $2,70 \pm 0,56 \mathrm{lt})$ and maximal voluntary ventilation $(127,91 \pm 29,48 \mathrm{lt} / \mathrm{min} \mathrm{vs} .109,10$ $\pm 19,07 \mathrm{lt} / \mathrm{min})$ were higher in the additionally trained group than others $(\mathrm{p}<0,001)$. Also, their vital capacity higher as $\% 31,50$, forced vital capacity as $\% 29,82$ and maximal voluntary ventilation as \% 17,24 in percentages. The results indicate that regular training in childhood and adolescence enhances lung volumes and functions. Therefore, it is predicted that promoting in-school physical activity hours and/or out-school physical activity levels would improve respiratory system and health.
\end{abstract} Anahtar kelimeler:
Solunum sistemi,
vital kapasite,
akciğer kapasitesi,
adölesan

\section{improve respiratory system and health.}

* Bu çalışma, 13. Uluslararası Spor Bilimleri Kongresi'nde (Konya) sunulmuştur.

† Sorumlu Yazar: Tuba Melekoğlu, tel: 02423106828, E-posta: tmelekoglu@ akdeniz.edu.tr

\section{Original Article}

Article Info Received: 12.04 .2018 Accepted: 24.06 .2018 Online Published: 30.06 .2018

\author{
Keywords: \\ Respiratory system, \\ vital capacity, \\ lung capacity, \\ adolescent
}




\section{GíRiş}

Fiziksel aktivite fizyolojik ve psikolojik sağlığın iyi olmasıyla ilişkilendirilmiştir. Birçok araştırmacı düzenli antrenmanın dolaşım sistemi, kas-iskelet sistemi, vücut kompozisyonu, aerobik ve anaerobik kapasite ve solunum sistemi üzerine olumlu etkilerini bildirmiştir (Sallis, Prochaska, \& Taylor, 2000; Van, Paw, Twisk, \& Van, 2007).

Özellikle çocuklukta ve ergenlikte yapılan fiziksel aktivitelerin sağlık üzerine önemli faydaları bulunmaktadır. Bildirilen bu olumlu etkilere karşın çocuk ve adölesanların fiziksel aktiviteler için ayırdıkları zaman gittikçe azalmaktadır. Son yıllarda fiziksel aktivite alışkanlıklarına ayrılan zamanın yerini iPod, cep telefonu, bilgisayar, televizyon gibi elektronik cihazlarla harcanan zaman almıştır (Janssen, Katzmarzyk, Boyce, King, \& Pickett, 2004). Fiziksel aktivitelere harcanan zaman azaldıkça obezite, kas-iskelet sistemi rahatsızlıkları, diyabet, solunum sistemi vb. hastalıkların insidansı artmıştır (Chau, Chey, Burks-Young, Engelen, \& Bauman, 2017; Peterson, 2016).

Bir kişinin egzersize katılabilmesi için en önemli faktörlerden birisi oksijen taşıma kapasitesidir (Andrew, Becklake, Guleria, \& Bates, 1972) Bu nedenle fiziksel aktiviteye katılan ve katılmayan kişiler oksijen taşıma kapasiteleri karşılaştırılarak birbirinden ayırt edilebilir. Benzer şekilde, solunum sisteminin gelişmiş olması da önemli bir faktördür (Hamilton \& Andrew, 1976).

Fiziksel aktivitelere veya spora katılım, solunum kaslarının güçlendirilmesinde ve solunum fonksiyonlarında iyileşmede yardımcı olabilir. Sedanter yaşam tarzına sahip kişiler, fiziksel olarak aktif yaşıtlarına kıyasla pulmoner fonksiyon parametreleri daha az gelişmiştir. Sedanter yaşam tarzı, obezite, akciğer fonksiyonunun kısıtlanması ve kardiyovasküler hastalıkların gelişimine neden olabileceği bildirilmiştir (Prakash, Meshram, \& Ramtekkar, 2007). Yapılmış olan araştırmalarda en az 1 yıllık antrenman periyodundan sonra özellikle yüzmenin akciğer hacim ve kapasitelerini arttırdığ akciğer hacimlerinin de arttığı bildirilmiştir (Jeličić, Uljević, \& Zenić, 2017; Lazovic ve diğerleri, 2015; Mazic ve diğerleri, 2015). Başka bir araştırma da; uzun periyotlu (26 ay) koşu antrenmanlarının, çocuklarda yaşa bağlı boy artışıyla beklenen akciğer hacmini, daha fazla arttırdığını bildirmiştir (Gaultier \& Crapo, 1997).

Astım, kronik obstrüktif akciğer hastalığı (KOAH) gibi solunum sistemi rahatsızlıkları genel sağlığ ve yaşam kalitesini olumsuz olarak etkilemektedir. Bununla birlikte düzenli egzersizlere bağlı olarak oluşan akciğer sağlığına yönelik anlık ve kalıcı kazanımların, bu hastalıkların oluşumunda, seyrinde ve tedavisinde olumlu etkileri bulunmaktadır. Aynı zamanda egzersizlere katılmakta zorluk yasayan astımlı çocuklarda, maksimal oksijen tüketim kapasitesindeki (VO2max) artış önemlidir. Astımlı kişilerde VO2max artışı, aerobik gücü arttırmakta ve egzersize bağlı bronkokonstriksiyon uyaranlarını azalmaktadır. Astımın kontrol altına alınmasında düzenli fiziksel aktivitenin önemli bir bileşen olduğu bildirilmiştir. Hatta bazı araştırmalar; ilaç kullanım sıklığının, hastaneye kaldırılmanın, hırıltılı soluma ve 
doktora başvurma sıklığının antrenman uygulamaları sonrasında azaldığını rapor etmişlerdir (Morton \& Fitch, 2011; Welsh, Kemp, \& Roberts, 2005).

$\mathrm{Bu}$ çalışmanın amacı; okuldaki beden eğitimi derslerine ek olarak okul dışındaki fiziksel aktivitelere katılan 13-14 yaşındaki çocukların akciğer hacim ve kapasitelerini kıyaslamaktır. $\mathrm{Bu}$ amaçla; çeşitli spor branşlarında en az 5 yıl süreyle düzenli antrenmanlara katılan çocukların akciğer hacimleri ve solunum fonksiyonları ölçülmüş ve değerlendirilmiştir.

\section{YÖNTEM}

\section{Araştırma Grubu}

Araştırmaya katılacak olan gönüllüleri belirlemek üzere Antalya ilinde 7. ve 8. sinıflarda okuyan 350 öğrenci ön değerlendirmeye tabi tutulmuştur. Antrenman geçmişlerine, sağl1k durumlarına, fiziksel özelliklerine bağlı ön değerlendirme sonrasında atletizm, futbol, hentbol, yüzme gibi branşlarda en az 5 yıllık antrenman geçmişine sahip 28 sporcu (yaş $13,54 \pm 0,51$ yıl, vücut ağırlığı $54,09 \pm 7,64 \mathrm{~kg}$, boy $162,68 \pm 7,48 \mathrm{~cm}$ ) ve antrenman geçmişi bulunmayan, sporcu grubundaki öğrencilere benzer fiziksel özelliklere sahip 28 sedanter (yaş

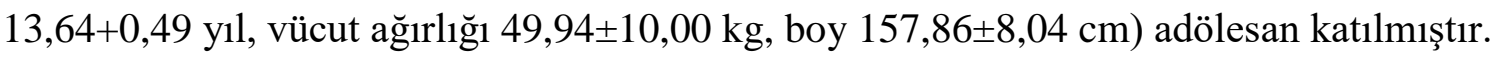

\section{Akciğer Hacim ve Kapasiteleri Ölçümü}

Akciğer hacim ve kapasitelerini belirlemek için spirometre ile vital kapasite (VC), zorlu vital kapasite (FVC) ve maksimal istemli ventilasyon (MVV) ölçümleri yapılmıştır. VC, FVC ve MVV ölçümleri Cosmed Pony FX (Italy) spirometre cihazı kullanılarak ölçülmüştür.

Vital Kapasite Ölçümü (VC): Gönüllüler normal solunum işini yaparken yavaş ama alabildiği kadar derin nefes alması ve sonra alınan havayı tamamıla ekspire etmesi istenmiştir. Test 3 kez tekrar edilmiş ve en iyi 2 sonuç arasındaki farkın $200 \mathrm{ml}$ ' den az olması durumunda en iyi değer çalışma verisi olarak kabul edilmiştir.

Zorlu Vital Kapasite Ölçümü (FVC): Maksimum bir inspirasyon sonrasında 6 sn' den kısa olmamak üzere olabildiğince hızlı ve güçlü ekspirasyon yapması istenmiştir. Burada da en iyi FVC değerleri arasındaki farkın 200 ml' den fazla olmaması koşuluyla en iyi test sonucu değerlendirilmeye alınmıştır.

Maksimal İstemli Ventilasyon Ölçümü $(M V V)$ : Kişinin bir dakika içinde alabileceği hava hacmini (lt/dk) tespit edebilmek amaciyla 12 sn süresince oturarak hızlı ve zorlu nefes alıp vermesi istenmiştir. Tekrarlanan 2 testten en iyi olanı kabul edilmiştir (Medicine, 2013). 
Melekoğlu, T., Işın, A., Ünlü G. (2018). Antrenmanın 13-14 yaş adölesanlarda solunum sistemi üzerine etkileri. Ulusal Spor Bilimleri Dergisi, 2(1),1-7.

\section{Verilerin Analizi}

Elde edilen verilerin basıklık ve çarpıklık değerleri (Tabachnick \& Fidell, 2007), histogram, normal Q-Q ve kutu grafiklerinin görsel değerlendirmesi ve Shapiro-Wilk testi (Shapiro \& Wilk, 1965), sonrasında, varyans homojenliği için Levene testi (Martin \& Bridgmon, 2012) uygulanmış ve verilerin normal dağıldığı tespit edilmiştir. Gruplar arası farklılığ değerlendirmek için Bağımsız Örneklem T testi uygulanmıştır. İstatistiksel anlamlılık düzeyi olarak $(\mathrm{p}<0.05, \mathrm{p}<0.01, \mathrm{p}<0.001)$ değerleri dikkate alınmıştır. Verilerin istatistiksel hesaplanmalarında SPSS 24 programı kullanılmıştır.

\section{BULGULAR}

Araştırmaya katılan adölesanların boy uzunluğu, vücut ağırlı̆̆ı, vücut yağ yüzdesi, akciğer hacimleri ve solunum kapasiteleri (VC, FVC ve MVV) ölçülmüştür. Tablo 1.'de gönüllülerin tanımlayıcı verileri gösterilmektedir ve Tablo 2.'de gönüllülerin akciğer hacimleri ve solunum kapasiteleri gösterilmektedir.

Tablo 1. Gönüllülerin tanımlayıcı verileri

\begin{tabular}{lcccc}
\multicolumn{1}{c}{ Değişkenler } & $\begin{array}{c}\text { SP } \\
(\text { Ort } \pm \text { SS })\end{array}$ & $\begin{array}{c}\text { SED } \\
(\text { Ort } \pm \text { SS) }\end{array}$ & t & p \\
\hline Yaş (yıl) & $13.64 \pm 0.48$ & $13.42 \pm 0.50$ & 1.616 & 0.112 \\
Boy Uzunluğu (cm) & $162.03 \pm 7.42$ & $158.57 \pm 6.82$ & 1.819 & 0.074 \\
Vücut Ăğırlığı (kg) & $53.76 \pm 7.60$ & $50.40 \pm 9.19$ & 1.491 & 0.142 \\
Vücut Yă̆ Yüzdesi (\%) & $15.99 \pm 8.28$ & $15.00 \pm 9.41$ & 0.419 & 0.677 \\
\hline
\end{tabular}

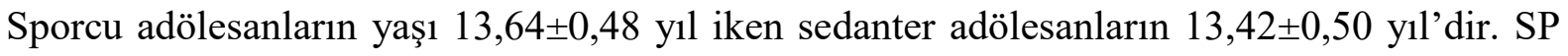
grubunun boy uzunluğu $162,03 \pm 7,42 \mathrm{~cm}$, vücut ağırlığ $53,76 \pm 7,60 \mathrm{~kg}$ ve vücut yağ yüzdesi $15,99 \pm 8,28$ iken SED grubunun boy uzunluğu $158,57 \pm 6,82 \mathrm{~cm}$, vücut ağırlı̆̆ $50,40 \pm 9,19 \mathrm{~kg}$ ve vücut yağ yüzdesi $15,00 \pm 9,41$ 'dir. Kontrol (SED) ve sporcu (SP) grubunun yaş, boy, vücut ağırlığı ve vücut yağ \%'leri arasında istatistiksel açıdan anlamlı farklılıklar bulunmamıştır $(\mathrm{p}>0,05)$.

Tablo 2. Gönüllülerin akciğer hacimleri ve solunum kapasiteleri

\begin{tabular}{lccccc}
\hline \multicolumn{1}{c}{ Değişkenler } & $\begin{array}{c}\text { SP } \\
(\text { Ort } \pm \text { SS })\end{array}$ & $\begin{array}{c}\text { SED } \\
(\text { Ort } \pm \text { SS })\end{array}$ & Fark \% & t & p \\
\hline VC (It) & $3.57 \pm 0.63$ & $2.72 \pm 0.56$ & 31.50 & 5.463 & 0.000 \\
FVC(It) & $3.50 \pm 0.64$ & $2.70 \pm 0.56$ & 29.82 & 5.105 & 0.000 \\
MVV(It/dk) & $127.91 \pm 29.48$ & $109.10 \pm 19.07$ & 17.24 & 2.532 & 0.014 \\
\hline
\end{tabular}

VC: Vital kapasite, FVC: Zorlu vital kapasite, MVV: Maksimal istemli ventilasyon

Sporcu adölesanlar sedanter adölesanlara göre sırasıyla vital kapasite $(3,57 \pm 0,63$ lt'ye karşı1n 2,72 $\pm 0,56$ lt), zorlu vital kapasite $(3,50 \pm 0,64$ lt'ye karşın 2,70 $\pm 0,56$ lt $)$ ve maksimal istemli ventilasyon $(127,91 \pm 29,48$ lt/dk'ya karşın $109,10 \pm 19,07$ lt/dk) değerleri anlamlı olarak yüksek bulunmuştur. Yüzdesel olarak değerlendirme yapıldığında sporcu adölesanlar 
Melekoğlu, T., Işın, A., Ünlü G. (2018). Antrenmanın 13-14 yaş adölesanlarda solunum sistemi üzerine etkileri. Ulusal Spor Bilimleri Dergisi, 2(1),1-7.

sedanter adölesanlar göre vital kapasiteleri \%31,50, zorlu vital kapasiteleri \%29,82 ve maksimal istemli ventilasyon değerleri \%17,24 daha yüksek tespit edilmiştir.

\section{TARTIŞMA VE SONUÇ}

Okuldaki beden eğitimi derslerine ek olarak okul dışındaki fiziksel aktivitelere katılan 13-14 yaşındaki adölesanların akciğer hacim ve kapasitelerini kıyaslamak amacıyla, antrenman geçmişlerine, sağlık durumlarına, fiziksel özelliklerine bağlı ön değerlendirme sonrasında atletizm, futbol, hentbol, yüzme gibi branşlarda en az 5 yıllık antrenman geçmişine sahip 28 sporcu ve antrenman geçmişi bulunmayan, sporcularla benzer fiziksel özelliklere sahip 28 sedanter, toplam 56 adölesan araştırmamıza katılmıştır.

$\mathrm{Bu}$ araştırmada düzenli antrenman geçmişine sahip çocukların sedanterlere göre akciğer hacim ve solunum kapasitelerinin daha gelişmiş olduğu tespit edilmiştir. Beden eğitimi derslerine ek olarak okul dışında da takım antrenmanlarına katılarak fiziksel aktivite düzeylerini arttıran adölesanların (SP) sadece beden eğitimi derslerine katılan adölesanlara (SED) göre sırasıyla vital kapasiteleri $(3,57 \pm 0,63$ lt'ye karşın 2,72 $\pm 0,561 \mathrm{t})$, zorlu vital kapasiteleri $(3,50 \pm 0,64$ lt'ye karşın 2,70 $\pm 0,56$ lt $)$ ve maksimal istemli ventilasyon $(127,91$ $\pm 29,48$ lt/dk'ye karşın 109,10 $\pm 19,07$ lt/dk) değerleri anlamlı olarak yüksek bulunmuştur. Araştırmamıza benzer şekilde Nourry ve ark. (2005) 8 haftalık yüksek şiddetteki koşu antrenmanlarının ergenlik öncesi çocuklarda solunum fonksiyonlarını arttırdığını ve egzersiz esnasında daha derin solunum yapmalarına neden olduğunu bildirmişlerdir. Berntsen ve ark. (2008) 9-10 yaşlarındaki çocuklarda akciğer fonksiyonlarını ölçmüşler ve fiziksel aktivite düzeyinin artışıyla akciğer fonksiyonlarının paralel olarak arttığını bildirmişlerdir.

Nikolić ve Ilić (1992) yaş ortalamaları 15 olan sporcu ve sedanter adölesanların solunum fonksiyonlarını karşılaştırdıkları çalışmalarında ise sporcu adölesanların sedanter adölasanlara kıyasla vital kapasitelerinin daha fazla gelişmiş olduğunu bildirmişlerdir. Doherty ve Dimitriou (1997) 10-21 yaşları arasındaki yüzücülerin sedanterlere kıyasla FVC değerlerinin daha yüksek olduğunu tespit etmişlerdir. Khrisanapant ve ark, (2011) 8 farklı spor branşında yer alan yaşları 13-19 arasında değişen 293 sporcu ve 295 sedanterlerin akciğer kapasiteleri açısından karşılaştırdıkları çalışma sonucu, düzenli egzersiz yapan öğrencilerin sedanter olanlara göre daha yüksek akciğer kapasiteleri olduğunu bildirmişlerdir. $\mathrm{Bu}$ çalışmada benzer şekilde, fiziksel aktiviteye katılanların katılmayanlara kıyasla akciğer kapasitelerinin daha gelişmiş olduğu tespit edilmiştir. Dolayısıyla, fiziksel aktiviteye katılan bireylerin daha yüksek ventilasyon kapasitesine sahip olabileceği öngörülmektedir. Fiziksel aktiviteye katılımın sadece iskelet uzuvlarının ve kalp kaslarının gücünü arttırmakla kalmayıp, aynı zamanda inspirasyon ve ekspirasyon için yardımcı kasları da geliştirdiği bildirilmiştir. Ayrıca aerobic gücün akciğer hacimleriyle pozitif ilişki içerisinde olduğu bildirilmiş ve erken yaşlarda sportif etkinliklere katılım ile akciğer hacim ve kapasitelerinin arttığ1 bildirilmiştir (Ghosh, Ahuja, \& Khanna, 1985; Hancox \& Rasmussen, 2018; Rasmussen \& Hancox, 2013). Lazovic ve dig. (2015) sportif aktivitelere katılımla birlikte 
solunumsal adaptasyonların oluştuğunu ve bu adaptasyonların katılım gösterilen aktivite türüne göre de değiştiğini bildirmişlerdir. Özellikle dayanıklılık sporlarına yönelik aktivitelere katılan sporcuların akciğer hacimlerinin, yeneteneğe ve güce dayalı branşlara nazaran daha yüksek olduğunu rapor etmişlerdir. Başka bir araştırmada da (Puente-Maestu \& Stringer, 2018), düzenli fiziksel aktivitelere katılım gösteren gençlerin fiziksel, fizyolojik ve psikolojik olarak daha sağlıklı olduğu belirtilmiştir. Araştırmalarının sonucunda solunum sağlığının ve fonksiyonlarının spora katılımla birlikte arttığını tespit etmişlerdir. Hasta olmasalar bile tüm yaş grupları için fiziksel aktivitelere katılımının teşvik edilmesiyle akciğere yönelik sağlığın geliştirilebileceğini bildirmişlerdir. Diğer taraftan çocukluk ve adölesan dönemde sedanter yaşam tarzının ilerleyen yaşlarda obezite ve kardiyovasküler hastalıklar için büyük bir risk faktörü olduğunu bildirmişlerdir.

Araştırma sonuçlarımıza göre spora katılımla birlikte akciğer kapasitelerinde artış tespit edilmiştir. Ayrıca VC ve FVC değerlerindeki yüzdesel farklılıklar (sırasıyla, \%31,50 ve \%29,82) benzerdir. Bu durum FVC değerlerinin VC değerlerine bağlantılı olarak geliştiğini göstermektedir. FVC değerlerini etkileyen faktörlerden birisi solunum kaslarının kuvvetidir. VC artışıyla beraber solunum kasları da güçlenerek FVC değerini etkilemektedir. Bununla birlikte solunum kaslarının kuvveti, solunum yollarının açıklığı ve nöromusküler koordinasyonun göstergesi olan MVV değerleri de \%17,24 oranında daha yüksek tespit edilmiştir. Benzer şekilde Mazic ve ark. (2015) sporcularda MVV değerini sedanterlere göre oldukça yüksek tespit etmişlerdir. Menezes ve ark. (2012) Brezilya'da yapmış oldukları kohort çalışma fiziksel antrenmanın solunum sistemi üzerine olumlu etkilerini vurgulamaktadır. 1993 yılında doğmuş olan 5265 çocuğun 15 yıllık takibi sonrasında, 4010 çocuğun akciğer fonksiyonlarını ölçmüşler ve fiziksel aktivite düzeyleriyle ilişkilendirmişlerdir. Araştırmalarının sonuncunda artan fiziksel aktivite düzeyiyle birlikte solunum fonksiyonlarının da arttığını bildirmişlerdir. Hollanda'da yapılan benzer bir uzunlamasına çalışmada 167 gönüllü 13 yaştan 27 yaşına kadar takip edilmiş ve fiziksel aktivite düzeyiyle paralel olarak FVC değerlerinin arttığını bildirmişlerdir (Twisk, Staal, Brinkman, Kemper, \& Van Mechelen, 1998).

Sonuç olarak akciğer hacimleri ve solunum kapasiteleri incelendiğinde, fiziksel aktiviteye katılan adölesanların VC, FVC ve MVV değerlerinin fiziksel aktiviteye katılmayan gruptan daha yüksek olduğu görülmektedir. Araştırmamızın sonuçları göstermektedir ki çocuklukta ve ergenlikte yapılan düzenli antrenmanlar akciğer hacim ve kapasitelerini geliştirmektedir. Özellikle akciğer hacimlerinde antrenmana bağlı önemli artış gözlemlenmektedir. Bu nedenle akciğer fonksiyonlarını ve genel sağlığı geliştirmek için, çocukları fiziksel aktivitelere yönlendirmek oldukça önemlidir.

\section{KAYNAKLAR}

Berntsen, S., Wisløff, T., Nafstad, P., \& Nystad, W. (2008). Lung function increases with increasing level of physical activity in school children. Pediatric exercise science, 20(4), 402-410.

Chau, J., Chey, T., Burks-Young, S., Engelen, L., \& Bauman, A. (2017). Trends in prevalence of leisure time physical activity and inactivity: results from Australian National Health Surveys 1989 to 2011. Australian and New Zealand journal of public health, 41(6), 617-624. 
Melekoğlu, T., Işın, A., Ünlü G. (2018). Antrenmanın 13-14 yaş adölesanlarda solunum sistemi üzerine etkileri. Ulusal Spor Bilimleri Dergisi, 2(1),1-7.

Doherty, M., \& Dimitriou, L. (1997). Comparison of lung volume in Greek swimmers, land based athletes, and sedentary controls using allometric scaling. British journal of sports medicine, 31(4), 337-341.

Ghosh, A., Ahuja, A., \& Khanna, G. (1985). Pulmonary capacities of different groups of sportsmen in India. British journal of sports medicine, 19(4), 232-234.

Hancox, R. J., \& Rasmussen, F. (2018). Does physical fitness enhance lung function in children and young adults? European Respiratory Journal, 51(2), 1701374.

Jeličić, M., Uljević, O., \& Zenić, N. (2017). Pulmonary Function in Prepubescent Boys: The Influence of Passive Smoking and Sports Training. Montenegrin Journal of Sports Science and Medicine, 6(1), 65-72.

Khrisanapant, W., Suttitum, T., \& Tunkamnerdthai, O. (2011). Lung Volume and Function in Male Adolescents in Northeast, Thailand: Students from Khon Kaen Sports School in Comparison with Other Schools in Khon Kaen Province. Srinagarind Medical Journal, 26(2), 98-105.

Lazovic, B., Mazic, S., Suzic-Lazic, J., Djelic, M., Djordjevic-Saranovic, S., Durmic, T., . . Zugic, V. (2015). Respiratory adaptations in different types of sport. Eur Rev Med Pharmacol Sci, 19(12), 2269-2274.

Martin, W. E., \& Bridgmon, K. D. (2012). Quantitative and statistical research methods: From hypothesis to results (Vol. 42): John Wiley \& Sons.

Mazic, S., Lazovic, B., Djelic, M., Suzic-Lazic, J., Djordjevic-Saranovic, S., Durmic, T., . . Zugic, V. (2015). Respiratory parameters in elite athletes-does sport have an influence? Revista Portuguesa de Pneumologia (English Edition), 21(4), 192-197.

Medicine, A. C. o. S. (2013). ACSM's guidelines for exercise testing and prescription: Lippincott Williams \& Wilkins.

Menezes, A. M., Wehrmeister, F. C., Muniz, L. C., Perez-Padilla, R., Noal, R. B., Silva, M. C., ... Hallal, P. C. (2012). Physical activity and lung function in adolescents: the 1993 Pelotas (Brazil) birth cohort study. Journal of Adolescent Health, 51(6), 27-31.

Nikolić, Z., \& Ilić, N. (1992). Maximal oxygen uptake in trained and untrained 15-year-old boys. British journal of sports medicine, 26(1), 36-38.

Nourry, C., Deruelle, F., Guinhouya, C., Baquet, G., Fabre, C., Bart, F., . . . Mucci, P. (2005). High-intensity intermittent running training improves pulmonary function and alters exercise breathing pattern in children. European journal of applied physiology, 94(4), 415-423.

Peterson, D. M. (2016). The benefits and risks of exercise. UpToDate, Waltham, MA.(Accessed on January 31, 2016.) Google Scholar.

Puente-Maestu, L., \& Stringer, W. W. (2018). Physical activity to improve health: do not forget that the lungs benefit too: Eur Respiratory Soc.

Rasmussen, F., \& Hancox, B. (2013). The effects of physical fitness on lung function from childhood to adulthood-The Odense schoolchild study: Eur Respiratory Soc.

Sallis, J. F., Prochaska, J. J., \& Taylor, W. C. (2000). A review of correlates of physical activity of children and adolescents. Med Sci Sports Exerc, 32(5), 963-975.

Shapiro, S. S., \& Wilk, M. B. (1965). An analysis of variance test for normality (complete samples). Biometrika, 52(3/4), 591-611.

Tabachnick, B. G., \& Fidell, L. S. (2007). Using multivariate statistics: Allyn \& Bacon/Pearson Education.

Twisk, J., Staal, B., Brinkman, M., Kemper, H., \& Van Mechelen, W. (1998). Tracking of lung function parameters and the longitudinal relationship with lifestyle. European Respiratory Journal, 12(3), 627634. 